\title{
Scattering Effects of Residential Trees on Very High Frequency Radio Wave Propagation
}

\author{
Adewumi Adebayo Segun ${ }^{1 *}$, Adewumi Hope Kofoworola ${ }^{2}$, Francis Dubem Chizea ${ }^{3}$, Ayantunji Gbenro \\ Benjamin $^{4}$, Ajani Sunday Adegbenro ${ }^{5}$ \\ ${ }^{1,2}$ Department of Pure and Applied Physics Ladoke Akintola University of Technology, Ogbomoso, Oyo State \\ Nigeria. \\ ${ }^{3,4}$ National Space Research and Development Agency, Abuja, Nigeria \\ ${ }^{5}$ Department of Physics, Kwara State University, Nigeria \\ *corresponding author: asadewumi@lautech.edu.ng
}

\begin{abstract}
Modeling of attenuation of Very High Frequency radio signal in residential environment can be very tedious as the channels are rarely characterized by vegetation of the same variety. This work focus on path loss measurement and attenuation modeling of the coherent scattered field intensity of VHF as it propagates through Mango and Jathropha trees. The two separate trees were illuminated uniformly with $2.15 \mathrm{dBi}$ dipole antenna connected to $60 \mathrm{~W}$ transmitter while 1.7dBi short dipole connected to GSP-730 Spectrum Analyzer was used for reception. Path loss due to each canopy were estimated relative to the scattering angles. Dry-matter fraction of the leave were determined using sensitive weigh balance and corresponding effective dielectric properties of the leaves and branches peculiar to each tree were estimated using semi-empirical formula. Specific attenuation models were developed separately for the two trees relative to dielectric properties of each tree leaves and branches. The results show that path loss due to single Mango tree canopy ranges from $100 \mathrm{~dB}$ to $140 \mathrm{~dB}$ and that of Jathropha ranges from $95 \mathrm{~dB}$ to $135 \mathrm{~dB}$. The results also show that total specific attenuation of the two trees depends on frequency, wavelength and dielectric properties of the canopies constituents
\end{abstract}

Keywords: Path loss; Radio Propagation; Residential Trees; Specific Attenuation Coefficient; VHF;

DOI: $10.7176 /$ APTA/83-11

Publication date: December $30^{\text {th }} 2020$

\section{Introduction}

Tree planting in residential environment is encouraged by government and non-governmental agencies, considering the social, environmental and economic importance in terms of oxygen provision and quality of air improvement, climatic amelioration, water conservation and soon. Hence, vegetation become an inherent component of most outdoor environment. Meanwhile, trees generally cause havoc to radio waves signal propagation by scattering, absorbing, diffracting and degrading its power, these effects have been a major issue of concern to radio link planners and has been an area of investigation for decades. In the past studies, efforts have been made by some radio researchers such as [1], [2], [3] and [4] to estimate the influence of tree canopy on radio waves propagation experimentally, and observations show that the scattering of radio waves from trees which are commonly found in residential environment is an important radio propagation mechanism. Hence the need for further investigation of the effects of tree canopy on radio waves propagation not only at Ultra High Frequency (UHF) but also at Very High Frequency (VHF) as these two frequency are well applied in radio wave broadcast. Proper evaluations and modeling of the effects of residential trees canopy on VHF radio wave in residential environment will enhance adequate link planning and budgeting of VHF radio link in residential Areas.

\section{Theory}

Vegetation is one of the significant features that affect radio wave propagation, it attenuates radio signal exponentially by scattering, diffraction and absorption through it irregular structure of leaves and branches 
(L\&B). Trees have mostly absorbing and scattering effects for propagation inside the trees layers and less diffraction effects mainly for the case of propagation over the trees as reported by [4], [5], [6], [7] and [8]. Scattering is important in many branches of Physics, though approaches differ depending on the relative length scales involved, the wavelength of the waves on one hand, and the size of the target (scatterer) on the other hand [9]. The scattering of electromagnetic waves by systems whose individual dimensions are small compared with a wavelength is a common and important occurrence. In such interaction it is convenient to think of the incident fields as inducing electric and magnetic multipoles that oscillate in definite phase relationship with the incident wave and radiate energy in directions other than the direction of incidence. The exact form of the angular distribution of radiated energy is governed by the coherent superposition of multipoles induced by incident fields and in general depends on the state of polarization of the incident wave. The differential cross section, summed over scattered polarization of electromagnetic wave by it target is given by [9] as

$\frac{d \sigma}{d \Omega}=k^{4} a^{6}\left|\frac{\epsilon_{r}-1}{\epsilon_{r}+2}\right|^{2} \frac{1}{2}\left(1+\cos ^{2} \theta\right)$

and the total scattering cross section is

$\sigma=\int \frac{d \sigma}{d \Omega} d \Omega=\frac{8 \pi}{3} k^{4} a^{6}\left|\frac{\epsilon_{r}-1}{\epsilon_{r}+2}\right|^{2}$

Coherent field incident inside canopy is given by [10] as;

$E_{i}(r)=E_{o} \exp \left\{-j \emptyset_{i}(r)\right\}$

where $E_{o}$ is the amplitude and $\emptyset_{i}$ is the phase. Coherent field inside the canopy is governed by the propagation constant given by[10] as;

$K=k+\frac{2 \pi}{k} F^{e q}\left(\hat{k}_{s}, \hat{k}_{i}\right)=k^{\prime}-j k^{\prime \prime}$

the attenuation constant $k^{\prime \prime}$ is nonzero and the coherent field attenuates as it propagates through the canopy. The specific attenuation in $\mathrm{dB} / \mathrm{m}$ is given by $[10]$ as

$\alpha_{c}=20 k^{\prime \prime} \log _{10} e=0.686 k^{\prime \prime}$

The imaginary part $k^{\prime \prime}$ is the reciprocal of the distance over which the amplitude is attenuated by a factor e which is given by [11] as

$k^{\prime \prime}=\frac{1}{\lambda_{0}}\left(\frac{\epsilon_{r} \mu_{r}}{2}\right)^{1 / 2}\left\{\left(1+\frac{1}{Q^{2}}\right)^{1 / 2}-1\right\}^{1 / 2}$

where, $\epsilon_{r}$ and $\mu_{r}$ are relative permittivity and relative permeability of the structural components of the tree canopy. $\mathrm{Q}$ is the ratio of displacement current density to the conduction current density given by [11] as;

$Q=\frac{\omega \varepsilon}{\sigma}$

The values of $\epsilon_{\text {leaf }}$ peculiar to each of the four branches is given by [12] as;

$\varepsilon_{\text {leaf }}=0.522\left(1-1.32 m_{d}\right) \varepsilon_{s w}+0.51+3.84 m_{d}$

$\varepsilon_{s w}$ is the dielectric permittivity for saline water according to Debye model and $m_{d}$ is the dry-matter fraction of leaves given by [12] as

$\varepsilon_{s w}=\varepsilon_{\infty}+\frac{\varepsilon_{S}-\varepsilon_{\infty}}{1-i \omega \tau}+i \frac{\sigma}{\omega \varepsilon_{0}}$ 
The value of the different parameters are $\tau=1.0 \times 10^{-11} s, \varepsilon_{\infty}=5.27, \varepsilon_{S}=80.0, \varepsilon_{o}=8.854187817 \times$ $10^{-12} \mathrm{~F} / \mathrm{m}$

Since the saline water of the leaf causes the largest contributions to the disturbance of the incident electromagnetic field, a model (eqn.9) of the water content will serve as a basis [12]. $\sigma$ is conductivity and taken to be (3-6)S $/ \mathrm{m}$. Saline water present in leaf is given by [12] as;

$m_{d}=\frac{\text { dry mass }}{\text { fresh mass }}$

In this work $m_{d}$ was obtained using digital weighing balance. The value of the permittivity of branches was estimated in (9) using the fact that the dry-matter fraction $\left(m_{d}\right)$ of the branches stays rather constant during the whole year and since the leaves have values around 0.3-0.4 at the beginning of the autumn, the same value was assumed for the branches. where permittivity of branches is given by [12] as

$\varepsilon_{\text {branch }}=0.24 \varepsilon_{s \omega}+2.05$

The average value of $m_{d}$ obtained from each tree canopy was used to determine the permittivity of branches. After obtaining the required data from both Mango and Jathropha canopies experimentally, appropriate substitutions were made to equations $7,8,9,10$ and 11 and the results obtained were further substituted to equation 6 to obtain each canopy components of attenuation propagation constant $k^{\prime \prime}$ which was used to determine specific attenuation caused by each canopy constituents (Table $1 \& 2$ ).

\section{Review of Previous Work}

Theoretical approach was used by [13],[14] and [15] for single scattering to calculate the absorption effects of trees using Born approximation for cases where the dielectric permittivity of the scatterer is closed to unity. Twersky [13] described the effects of multiple scattering from discrete scatterer using statistical approach. Karam used the geometrical optics approximation that satisfies Feynman diagram to account for absorbing amplitude and phase effects from trees, using real physical conductivity and random distribution of branches and leaves as adopted in this work. Investigations of tree canopy effects on radio channel characteristics have been more focused on coherent scattering due to its obvious attenuation of radio waves propagation through foliage as deduced by [15], [16]. [17], [18] and [19].

\section{Measurement Equipment and Procedure}

In this work the wave propagation is in three-dimensional space and the two trees are modeled as finite cylindrical volume consisting of randomly located and oriented branches and leaves, modeled as dielectric cylinders and disks (Fig. 2a and Fig. 2b). Path loss and specific attenuation due to coherent tree scattering of VHF radio waves by Jathropha and Mango canopies (Fig.1a and Fig.1b) were investigated by adopting forward scattering propagation mechanism approach (Fig.2c). A 6Watts transmitter was placed as the source of incident field at two different heights of $1.7 \mathrm{~m}$ and $2.25 \mathrm{~m}$ consecutively and the reception height was fixed at $1.5 \mathrm{~m}$. Four major branches with multiple minor branches were identified on the Mango and Jathropha canopies. Measurement was initially taken at scattering angle of 90degree to the incident ray and further measurements were taken at additional 30degree interval to determine the power loss due to scattering. Specific attenuation of each branch relative to its dielectric

property were estimated using existing equations. The differential cross sections for scattering with polarization average over initial polarizations were deduced for each canopy. 


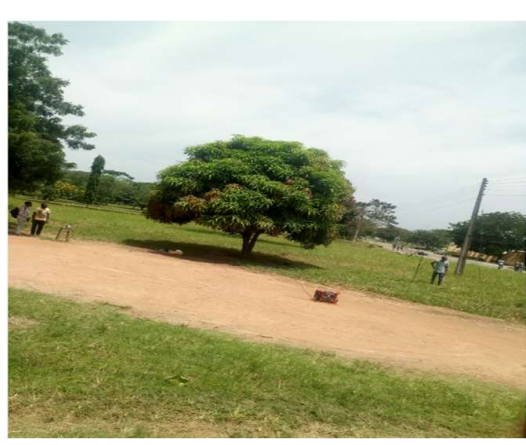

Fig. 1(a): Mango tree

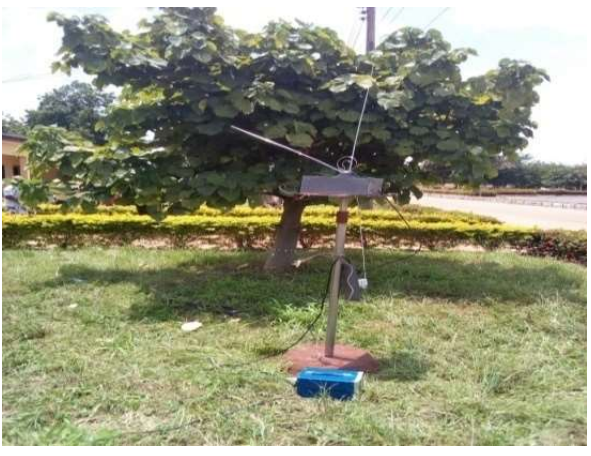

Fig. 1(b): Jathropha tree

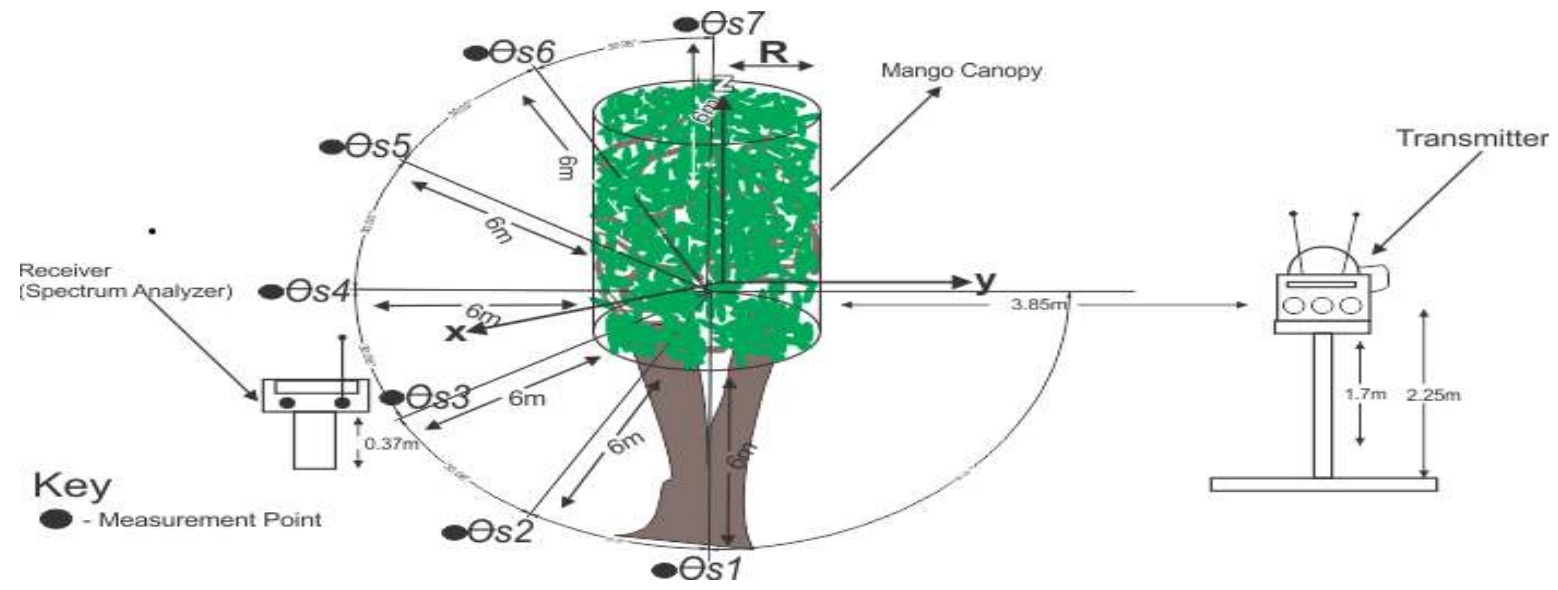

Fig.2a: Schematic diagram of the Mango canopy volume

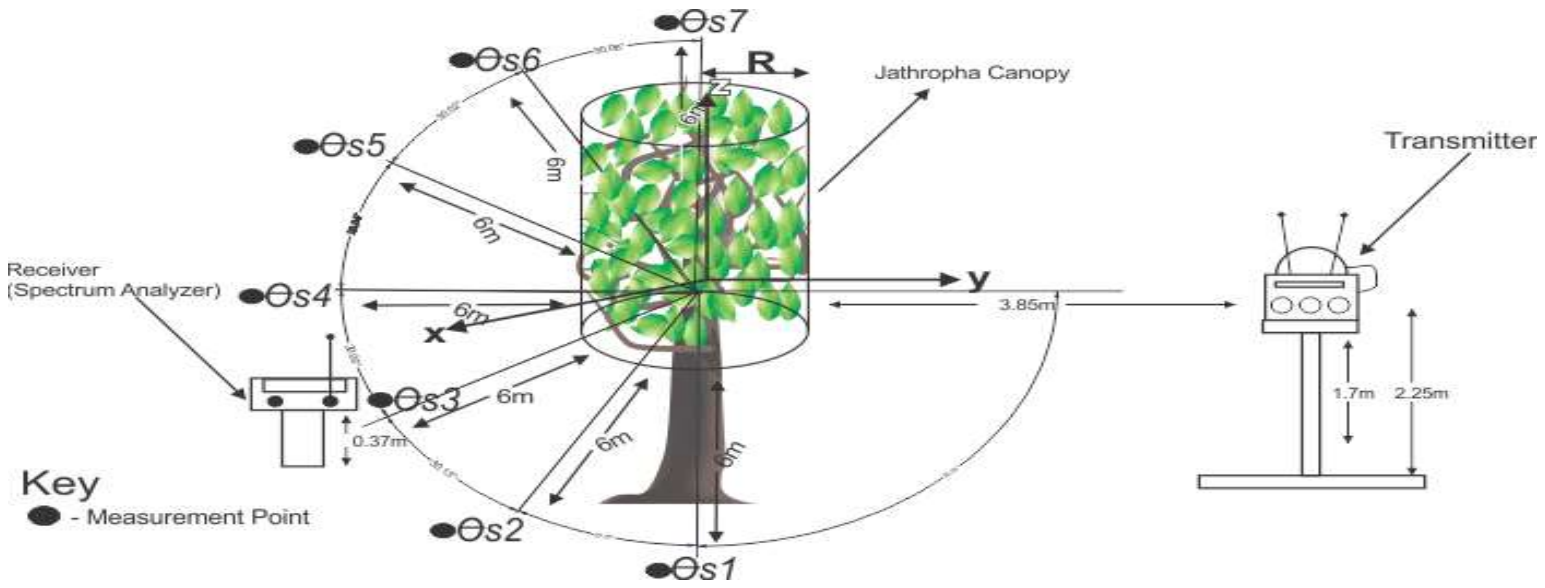

Fig. 2b: Schematic diagram of Jathropha canopy volume 


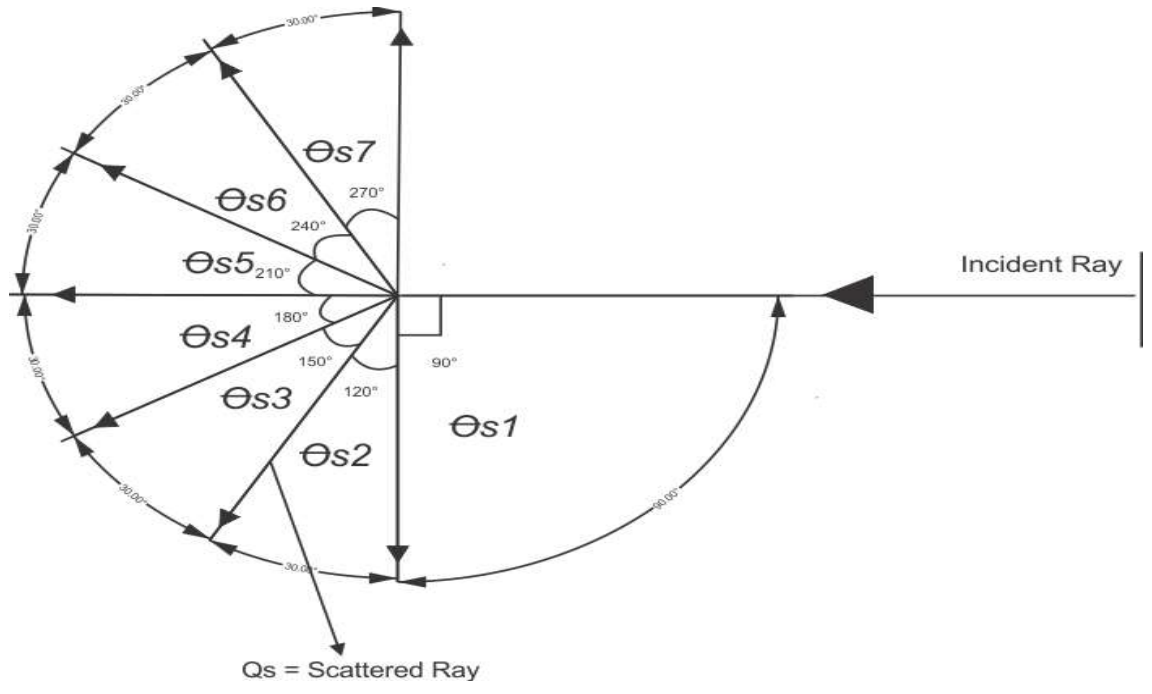

Fig. 2c: Front view of the scattered waves

\section{DATA ANALYSIS}

Table1: Mango tree canopy parameters and Properties

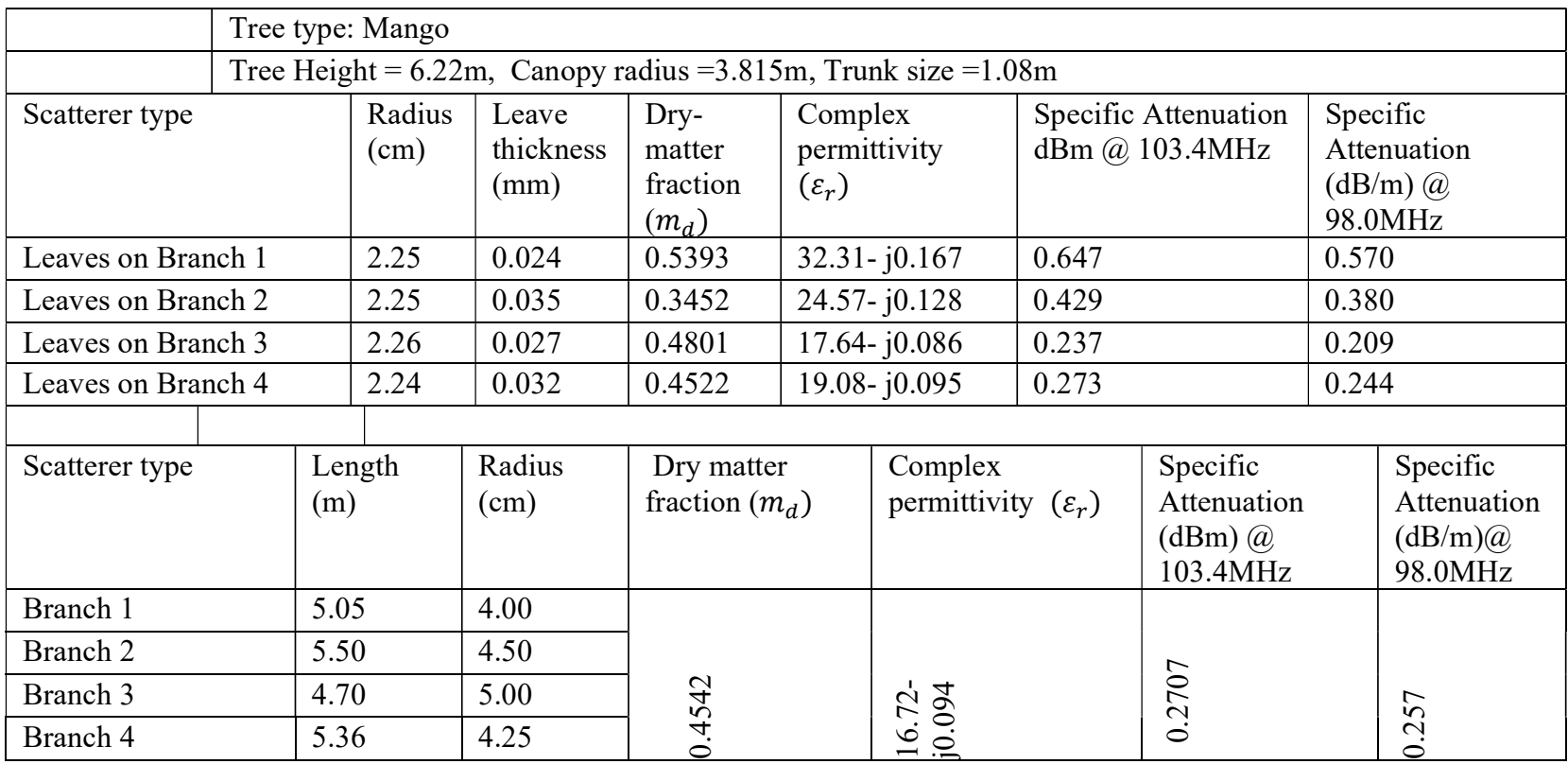


Table 2: Jathropha tree canopy parameters and Properties

\begin{tabular}{|c|c|c|c|c|c|c|c|c|}
\hline & \multicolumn{8}{|c|}{ Tree type: Jathropha } \\
\hline & \multicolumn{8}{|c|}{ Tree Height $=3.59 \mathrm{~m}$, Canopy radius $=2.065 \mathrm{~m}$, Trunk size $=0.73 \mathrm{~m}$} \\
\hline \multicolumn{2}{|l|}{ Scatterer type } & $\begin{array}{l}\text { Radius } \\
(\mathrm{cm})\end{array}$ & \multicolumn{2}{|c|}{$\begin{array}{l}\text { Leave } \\
\text { thickness } \\
(\mathrm{mm})\end{array}$} & $\begin{array}{l}\text { Dry-matter } \\
\text { fraction } \\
\left(m_{d}\right)\end{array}$ & $\begin{array}{l}\text { Complex permittivity } \\
\left(\varepsilon_{r}\right)\end{array}$ & $\begin{array}{l}\text { Specific Attenuation } \\
(\mathrm{dBm}) @ 103.4 \mathrm{MHz}\end{array}$ & $\begin{array}{l}\text { Specific } \\
\text { Attenuation } \\
(\mathrm{dB} / \mathrm{m}) @ \\
98.0 \mathrm{MHz}\end{array}$ \\
\hline \multicolumn{2}{|c|}{ Leaves on Branch 1} & 6.50 & \multicolumn{2}{|l|}{0.015} & 0.3216 & $25.78-\mathrm{j} 0.135$ & 0.467 & 0.412 \\
\hline \multicolumn{2}{|c|}{ Leaves on Branch 2} & 6.35 & \multicolumn{2}{|l|}{0.019} & 0.2645 & $28.71-\mathrm{j} 0.153$ & 0.561 & 0.491 \\
\hline \multicolumn{2}{|c|}{ Leaves on Branch 3} & 6.30 & \multicolumn{2}{|l|}{0.017} & 0.2872 & $27.54-\mathrm{j} 0.146$ & 0.523 & 0.461 \\
\hline \multicolumn{2}{|c|}{ Leaves on Branch 4} & 6.45 & \multicolumn{2}{|l|}{0.016} & 0.3078 & $26.48-\mathrm{j} 0.139$ & 0.489 & 0.427 \\
\hline Scatterer type & $\begin{array}{l}\text { Length } \\
\text { (m) }\end{array}$ & \multicolumn{2}{|c|}{ Radius (cm) } & \multicolumn{2}{|c|}{$\begin{array}{l}\text { Dry matter fraction } \\
\left(m_{d}\right)\end{array}$} & $\begin{array}{l}\text { Complex permittivity } \\
\left(\varepsilon_{r}\right)\end{array}$ & $\begin{array}{l}\text { Specific Attenuation } \\
\text { (a) } 103.4 \mathrm{MHz}\end{array}$ & $\begin{array}{l}\text { Specific } \\
\text { Attenuation } \\
(\mathrm{dB} / \mathrm{m}) @ \\
98.0 \mathrm{MHz}\end{array}$ \\
\hline Branch 1 & 2.38 & \multicolumn{2}{|l|}{4.00} & \multirow{4}{*}{\multicolumn{2}{|c|}{ กิ }} & \multirow{4}{*}{$\begin{array}{l} \pm \\
\dot{0} \\
\dot{D} \\
\stackrel{\sim}{v} \\
\dot{v}\end{array}$} & \multirow{4}{*}{$\stackrel{g}{+}$} & \multirow{4}{*}{ 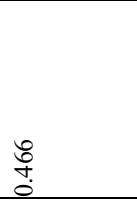 } \\
\hline Branch 2 & 2.64 & 3.70 & & & & & & \\
\hline Branch 3 & 2.37 & 3.50 & & & & & & \\
\hline Branch 4 & 2.37 & 3.00 & & & & & & \\
\hline
\end{tabular}

\section{Results and Discussion}

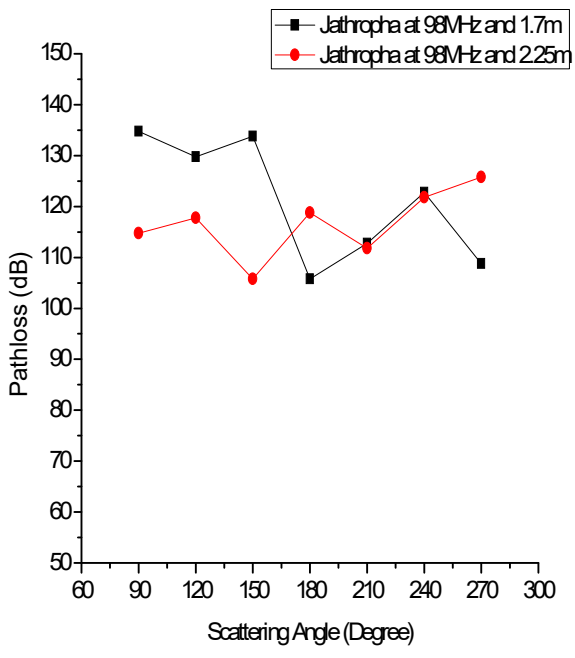

Fig.1a: Path loss due to Jathropha at $98 \mathrm{MHz}$

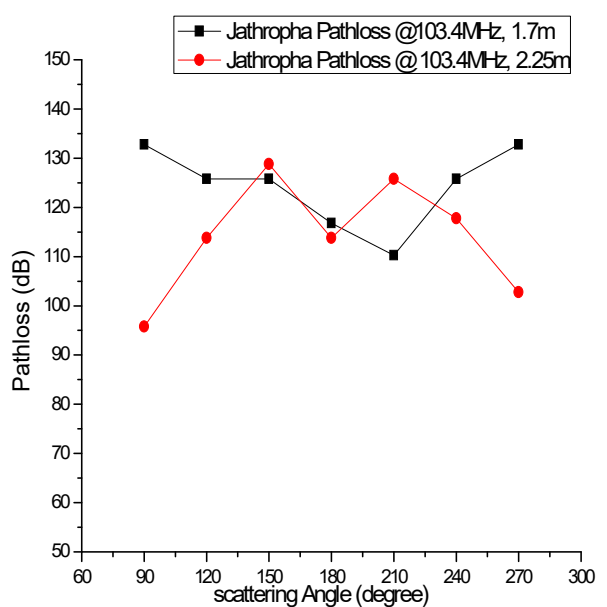

Fig1b :Path loss due to Jathropha at $103.4 \mathrm{MHz}$

Fig $1 \mathrm{a}$ and $1 \mathrm{~b}$ show the measure path loss due to Jathropha tree relative to the scattering angles at distance of $6 \mathrm{~m}$ away from the canopy and at transmitting height of $1.7 \mathrm{~m}$ and $2.25 \mathrm{~m}$ with transmitting frequency of $98 \mathrm{MHz}$ and $103.4 \mathrm{MHz}$ respectively. the path loss ranges from $95 \mathrm{~dB}$ to $135 \mathrm{~dB}$ and averagely higher at Transmitting height of $1.7 \mathrm{~m}$ than $2.25 \mathrm{~m}$ due to tree canopy branches and leaves geometry at different height. 


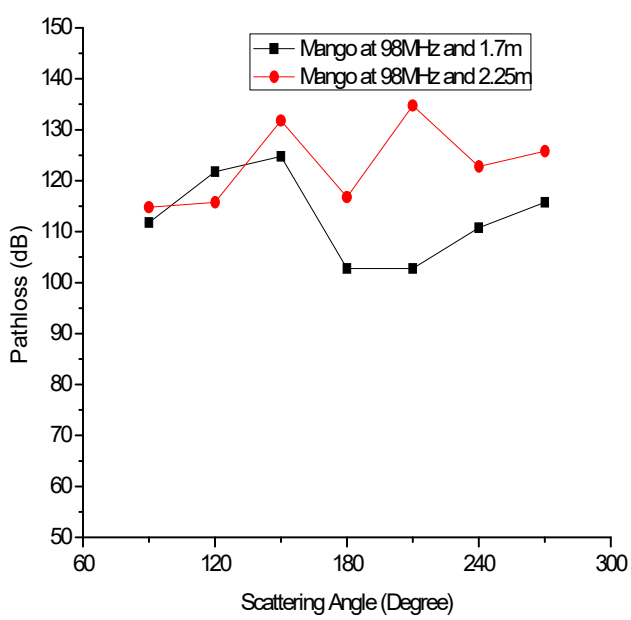

Fig.2a: Path loss due to Mango canopy at $98 \mathrm{MHz}$

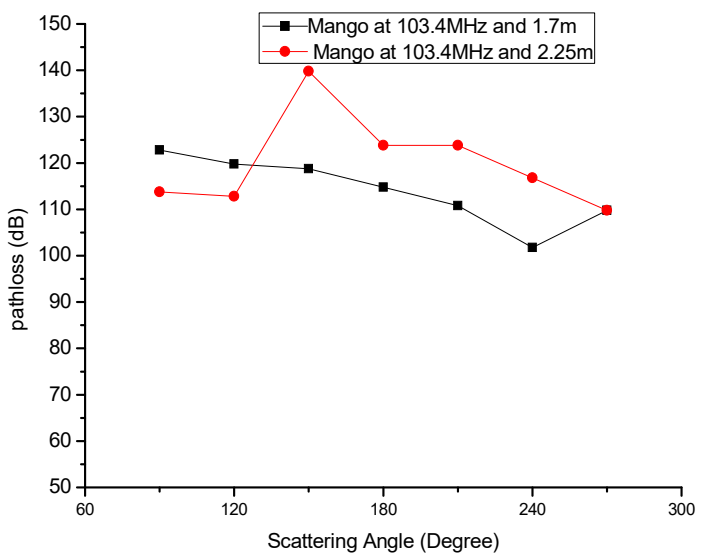

Fig2b: Path loss due to Mango canopy at $103.4 \mathrm{MHz}$

In fig.2a and fig $2 \mathrm{~b}$, the measured path loss due to Mango tree scattering ranges from $100 \mathrm{~dB}$ to $140 \mathrm{~dB}$ with path loss averagely higher at $2.25 \mathrm{~m}$ than $1.7 \mathrm{~m}$ at both frequency of $98 \mathrm{MHz}$ and $103.4 \mathrm{MHz}$. The variation in path loss with height in the case is also due to tree canopy geometry.
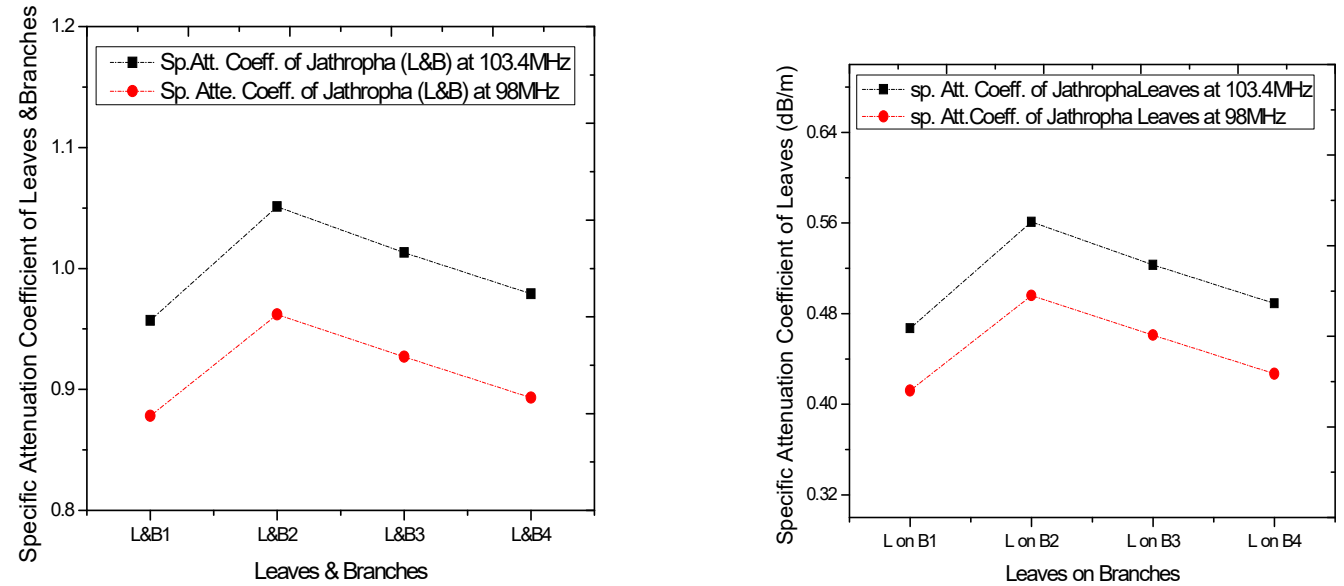

Fig.3a: Specific attenuation coefficient of Jathropha Leaves \& branches Fig.3b: Specific attenuation coefficient of Jathropha Leaves 

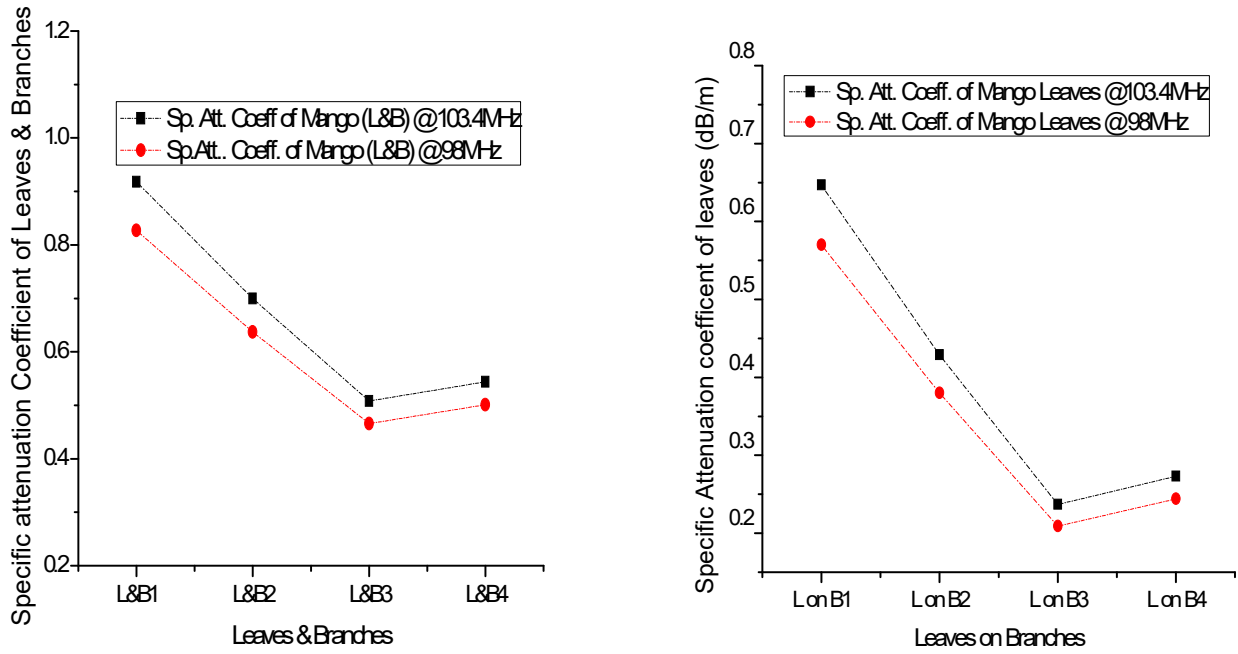

Fig.4a: Specific attenuation coefficient of Mango Leaves \& branches

Fig. 4b: Specific attenuation coefficient of Mango Leaves

Specific Attenuation coefficient parameters due to each canopy constituents (branches and leaves) relative to the frequency of $98 \mathrm{MHz}$ and $103.4 \mathrm{MHz}$ were measured and computed (Table 1and 2). Fig. 3a and Fig. 3b show the comparison of specific attenuation coefficient of Jathropha leaves and branches combined and that of leaves alone at the measured frequencies. In Fig. 3a, the specific attenuation of both branches and leaves on each branch ranges from $0.85 \mathrm{~dB}$ to $1.5 \mathrm{~dB}$ while that of leaves alone ranges from $0.41 \mathrm{~dB}$ to $0.56 \mathrm{~dB}$ as depicted in Fig. $3 \mathrm{~b}$ and it averagely higher at $103.4 \mathrm{MHz}$ than $98 \mathrm{MHz}$. This shows that specific attenuation of VHF is canopy constituents and frequency depend. Fig. $4 \mathrm{a}$ and Fig. $4 \mathrm{~b}$ show that the specific attenuation of mango leaves and branches ranges from $0.4 \mathrm{~dB}$ to $0.93 \mathrm{~dB}$ and that of leaves only ranges from $0.2 \mathrm{~dB}$ to $0.65 \mathrm{~dB}$. The results show averagely higher specific attenuation at higher frequency.

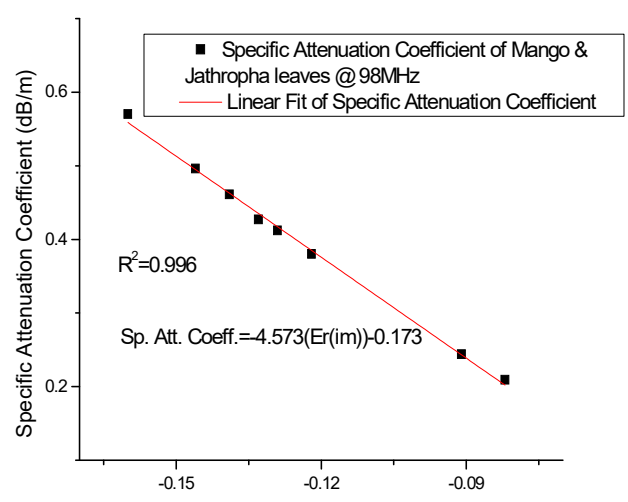

Imaginary Values of Attenuation constant of Mango \& Jathropha Leaves

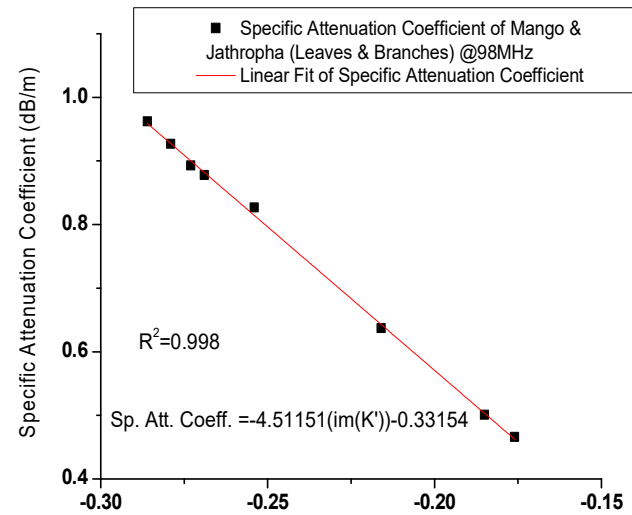

Imag. Values of Attenuation constant of Mango \& Jathropha Leaves\& Branches

Fig.5a: Fitted curve of spec. att. coeff. of Leaves \& Branches at 98MHz Fig.5b: Fitted curve of spec. att. coeff. of Leaves at $98 \mathrm{MHz}$ 

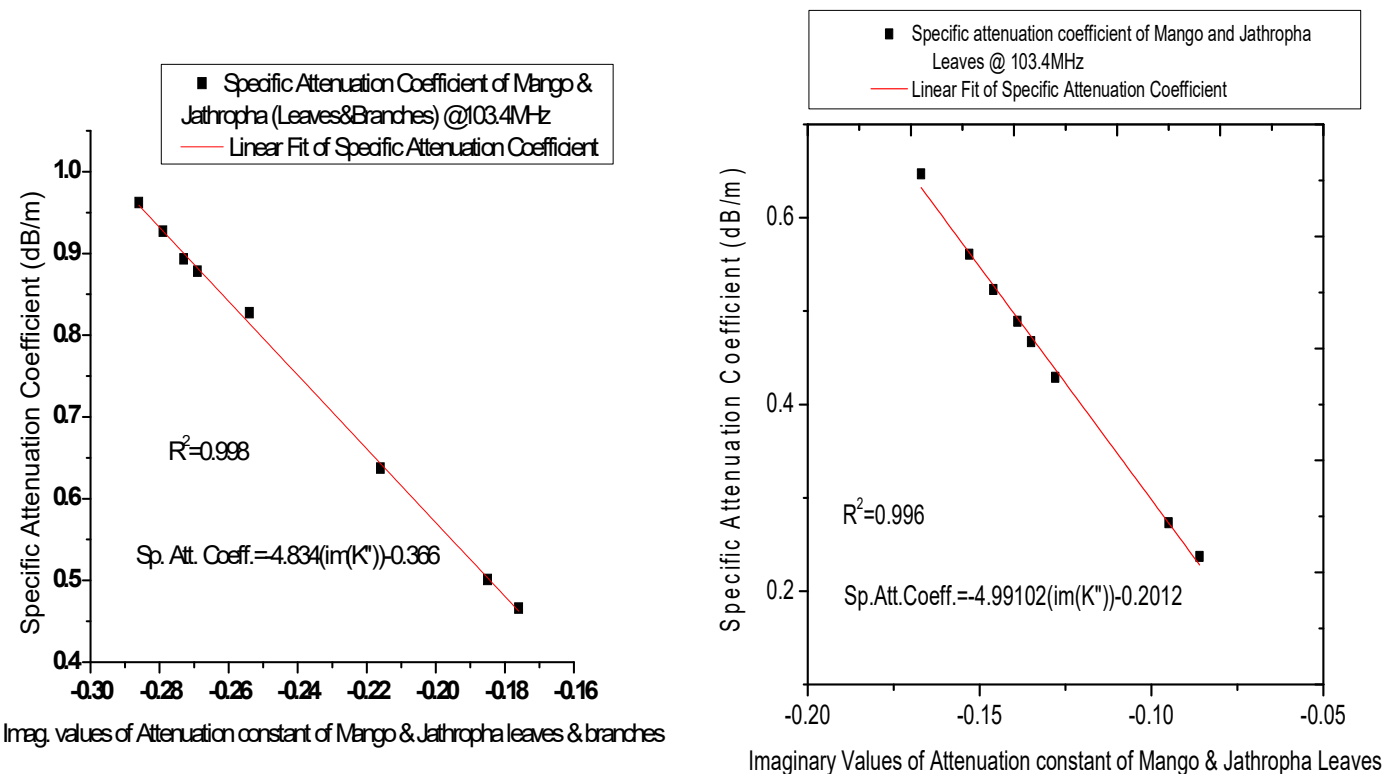

Fig.6a: Fitted curve of spec. att. coeff. of Leaves \& Branches at $103.4 \mathrm{MHz}$ Fig.6b: Fitted curve of spec. att. coeff. of Leaves only at $103.4 \mathrm{MHz}$

Fig. 5a and Fig. 5b show the attenuation model developed for both Jathropha and Mango trees constituents. First, for branches with leaves (Fig 5a) and later for leaves only (Fig. 5b) respectively at 98MHz. The two graphs show decrease in specific attenuation coefficient with increase in imaginary values of attenuation constant of the mango branch and leave. The developed models give gradient coefficient of $4.5115 \mathrm{~dB} / \mathrm{m}$ for branches and leaves and $4.573 \mathrm{~dB} / \mathrm{m}$ for leaves respectively with coefficient of determination $\left(\mathrm{R}^{2}\right)$ of 0.998 and 0.996 . In Fig. 6a and Fig. $6 \mathrm{~b}$, specific attenuation coefficient also decreases with increase in the imaginary values of attenuation constant of Jathropha tree with gradient coefficient of $4.834 \mathrm{~dB} / \mathrm{m}$ for branches and leaves and $4.998 \mathrm{~dB} / \mathrm{m}$ for leaves only with coefficient of determination $\left(\mathrm{R}^{2}\right)$ of 0.998 at $103.4 \mathrm{MHz}$

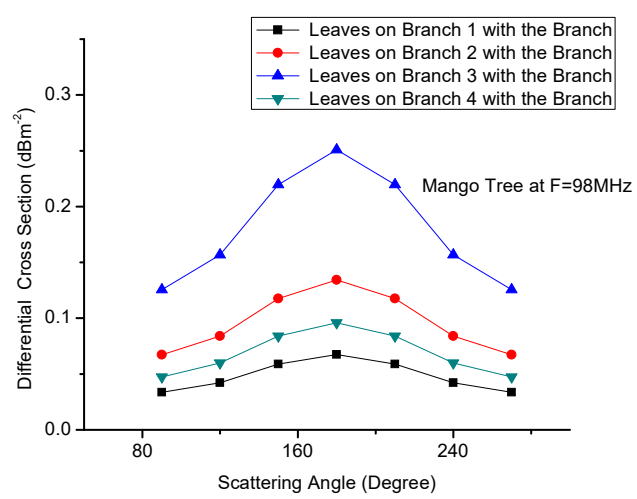

Fig. 7a: Mango differential cross section at $98 \mathrm{MHz}$

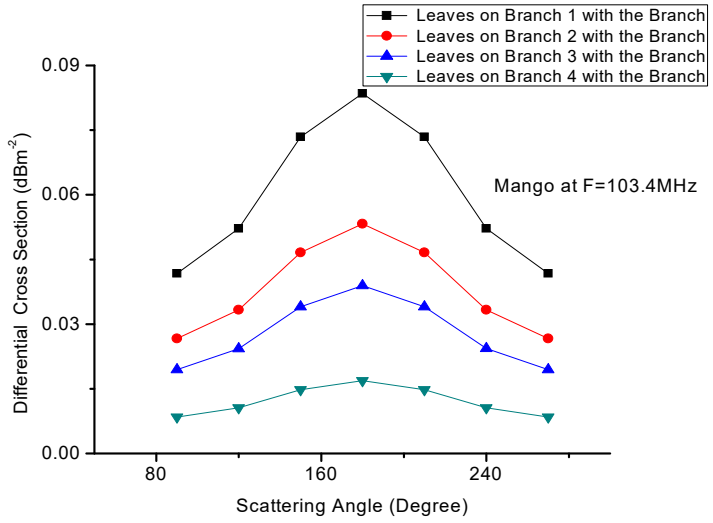

Fig. 7b: Mango differential cross section 103.4M 

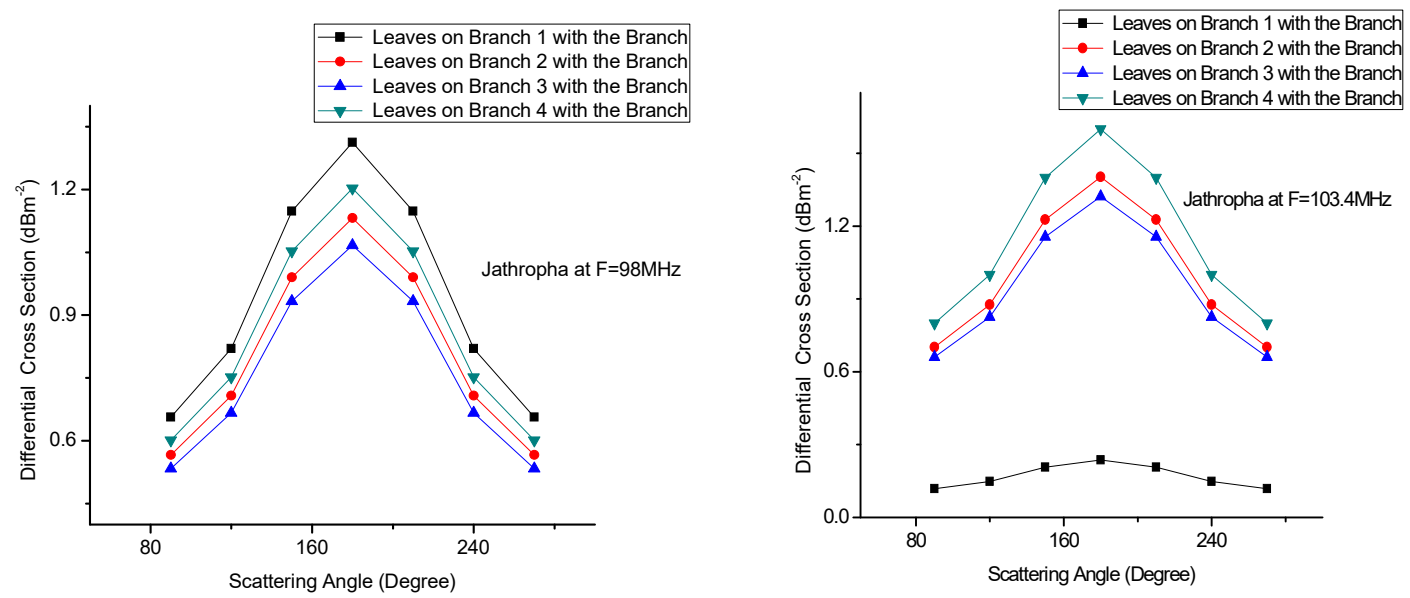

Fig.8a: Jathropha differential cross section at 98MHz. Fig. 8b: Jathropha differential cross section at $103.4 \mathrm{MHz}$

Fig. 7a, 7b, 8a and $8 \mathrm{~b}$ show the differential cross section sum over scattered polarization of branches and leaves of the two tress under investigation. All observations in the case show that the polarization has it maximum at angle $\theta=\pi / 2$. At this angle the scattered radiation is $100 \%$ linearly polarized perpendicular to the scattering plane and an appreciable range of angles on either side of $\theta=\pi / 2$ is quite significantly polarized.

\section{Conclusion}

Path loss and specific attenuation coefficient of a coherent scattered field of VHF radio wave as it propagates through stand alone Mango and Jathropha trees at $98 \mathrm{MHz}$ and $103.4 \mathrm{MHz}$ have been analyzed. The results show that Path loss is more significant at scattering angles with higher leaves density and the total specific attenuation depends on frequency of transmission, height of the transmitter, wavelength of the transmitted signal and dielectric properties of the trees canopies constituents. Also, VHF signal is linearly polarized perpendicular to the scattering angle and maximum at angle 180 degree for residential trees canopies. The proposed tree scattering model will enhanced prediction of path loss and specific attenuation of VHF radio wave propagation through trees of different variety in residential environment and also assist in VHF radio link planning and budgeting in residential places.

\section{References}

[1] Y.S Meng and Y.H Lee (2010) Investigations of foliage effect on Modern Wireless Communication Systems: A Review, Progress in Electromagnetic Research Vol. 105, 313- 332

[2] N. Blaunstein, D. Censor, D. Katz, A. Freedman and I. Matityahu (2012) Radio Propagation in Rural Residential Areas with Vegetation Journal of Electromagnetic waves and Applications Vol. 17, 1029- 1041

[3] Weissberger M.A (1982)., "An initial critical summary of models for predicting the attenuation of radio waves by foliage,"ECAC-TR-81-101, Electromagnetic compact Analysis Center, Annapolis, Maryland, final report.

[4] Ishimaru A."Wave propagation and scattering in random media. Academic press, New York 1978.

[5] Mahmoud Elshayeb and Silvello Betti (2018) Study of Attenuation in vegetation media and Prediction Model at microwave Frequencies Vol.7, Issue 1. Science Journal of Circuits, Systems and Signal processing page 1-7

[6] Meng, Y. S., Lee Y. H., and Ng B. C. 2009, Study of propagation loss prediction in forest environment, Progress in Electromagnetic Research B, Vol. 17, pp.117-133.

[7] M. A Karam and A. K Fung, "Electromagnetic wave scattering from a layer of finite length, randomly oriented, dielectric, circular cylinders over a rough interface with application to vegetation," int. J. Remote Sensing, Vol. 9, no. 6, pp. 1109-1134, 1988.

[8] M.A Karam, A.K Fung and Y.M.M Antar " Electromagnetic wave scattering from some vegetation samples," IEEE Trans. Antenna propagation; vol. 46, pp. 872-880, June 1998.

[9] J. D Jackson, 1998 "Classical Electrodynamics", third edition, John Wiley \& Sons. Inc. New York, ISBN 0471-30932. 
[10] W. Yvo L. C. de Jong and Matti H. A. J. Herben; A Tree scattering model for improved propagation prediction in Urban Microcells. IEEE Transaction on Vehicular Technology. Vol. 53, No.2, March 2004. [11] Matti H. A. J; Yvo L. C. de Jong and Herben; A Tree scattering model for improved propagation prediction in Urban Microcells. IEEE Transaction on Vehicular Technology. Vol. 53, No. 2, March 2004.

[12] F.T. Ulaby, T.E Van Deventer, J.R. East, T.F. Haddock, and M. E. Coluzzi, "Millimeter-wave bistatic scattering from ground and vegetation target, "IEEE Trans. Geosci. Remote Sensing, Vol. 26, pp.229-243, May 1988.

[13] Twersky, V., Multiple scattering of electromagnetic waves by arbitrary configurations, J. Math. Phys.' 8, 569- 610, 1967 Torrico, S. A, H. L., Bertoni, and R. H. Lang. Modeling tree effect on path loss in a residential environment. IEEE Trans. Antennas propagation., 46, 107-119,

[14] Tamir T, (1967), "On -radio-wave propagation in forest environments", IEEE trans. On Antenna and Propagation. AP-15, (6), pp 806- 817.

[15] Torrico, S. A., and R.H. Lang, Bistatic scattering effects from a tree in a vegetated residential environment, paper presented at National Union Radio Scientifique Internationale Meeting, Boulder, Colo., 1998. [16] Rodriguez, I., Abreu, R. B., Portela Lopes de Almeida, E., Lauridsen, M., Loureiro, A., \& Mogensen, P. E.(2016). $24 \mathrm{GHz}$ cmWave Radio Propagation Through Vegetation: Suburban Tree Clutter Attenuation. In 2016,10th European Conference on Antennas and Propagation (EuCAP) IEEE. DOI:10.1109/ EuCAP.2016.7481471.

[17] Masaki Hara, Hitoshi Shimasaki Yuichi Kado and Masatoshi Ichida (2016) Effect of Vegetation Growth on Radio propagation in 920-MHz Band, Institute of Electronics information and Communication, 81-86, Vol. E99B.

[18] Valentin Popov (2019) Cross Polarization effect of radio waves propagation by forest vegetation in wireless communication systems on transport. Elsevier, Science Direct procedia Science 149, 195- 201.

[19] Sergio Morgadinho, Juergen Richter, Rafael F. S., Caldeirinha and Telmo R. Fernandes (2012). Investigation of a Radio Propagation Model for vegetation Scatter Dynamic Channels at BFWA frequencies. Proceedings of the international conference on signal processing and multimedia Applications and wireless information Networks and systems page 329-339 